\title{
Quantitative analysis of the impact factors of con- ventional energy carbon emissions in Kazakhstan based on LMDI decomposition and STIRPAT model
}

\author{
LI Jiaxiu ${ }^{1,2,3}$, 'CHEN Yaning ${ }^{1}$, LI Zhi ${ }^{1}$, LIU Zhihui ${ }^{2}$ \\ 1. State Key Laboratory of Desert and Oasis Ecology, Xinjiang Institute of Ecology and Geography, CAS, \\ Urumqi 830011, China; \\ 2. College of Resource and Environment Science, Xinjiang University, Urumqi 830046, China; \\ 3. College of Resources and Environment, University of Chinese Academy of Sciences, Beijing 100049, China
}

\begin{abstract}
Quantitative analysis of the impact factors in energy-related $\mathrm{CO}_{2}$ emissions serves as an important guide for reducing carbon emissions and building an environmentally-friendly society. This paper aims to use LMDI method and a modified STIRPAT model to research the conventional energy-related $\mathrm{CO}_{2}$ emissions in Kazakhstan after the collapse of the Soviet Union. The results show that the trajectory of $\mathrm{CO}_{2}$ emissions displayed U-shaped curve from 1992 to 2013. Based on the extended Kaya identity and additive LMDI method, we decomposed total $\mathrm{CO}_{2}$ emissions into four influencing factors. Of those, the economic active effect is the most influential factor driving $\mathrm{CO}_{2}$ emissions, which produced $110.86 \mathrm{Mt} \mathrm{CO}_{2}$ emissions, with a contribution rate of $43.92 \%$. The second driving factor is the population effect, which led to $11.87 \mathrm{Mt} \mathrm{CO}_{2}$ emissions with a contribution rate of $4.7 \%$. On the contrary, the energy intensity effect is the most inhibiting factor, which caused $-110.90 \mathrm{Mt} \mathrm{CO}_{2}$ emissions with a contribution rate of $-43.94 \%$, followed by the energy carbon structure effect resulting in $-18.76 \mathrm{Mt} \mathrm{CO}_{2}$ emissions with a contribution rate of $-7.43 \%$. In order to provide an in-depth examination of the change response between energy-related $\mathrm{CO}_{2}$ emissions and each impact factor, we construct a modified STIRPAT model based on ridge regression estimation. The results indicate that for every $1 \%$ increase in population size, economic activity, energy intensity and energy carbon structure, there is a subsequent increase in $\mathrm{CO}_{2}$ emissions of $3.13 \%, 0.41 \%, 0.30 \%$ and $0.63 \%$, respectively.
\end{abstract}

Keywords: quantitative analysis; energy-related $\mathrm{CO}_{2}$ emissions; STIRPAT model; Kazakhstan

\section{Introduction}

Climate warming has recently emerged as a focus of major international concern due to the increasing frequency of natural disasters attributed to climate anomalous change (Arnell and Gosling, 2016; Nicogossian et al., 2017; Mccarl et al., 2016; Sauer et al., 2017). Greenhouse

Received: 2017-09-26 Accepted: 2017-11-08

Foundation: CAS Strategic Priority Research Program, No.XDA19030204; CAS Western Light Program, No.2015-XBQN-B-17

Author: Li Jiaxiu, PhD Candidate, specialized in climate change in central Asia. E-mail: 1ijiaxiu15@163.com

"Corresponding author: Chen Yaning, Professor, E-mail: chenyn@ms.xjb.ac.cn 
gas emissions have been theorized as the leading cause in global climate anomalies. Studies indicate that $\mathrm{CO}_{2}$ contributes about $60 \%$ of all greenhouse gases, and its emissions source mainly comes from burning fossil fuels due to human activities (Tunç et al., 2009; Ozturk and Acaravci, 2010). Along with the increase in energy consumption, the total emissions of greenhouse gases will inevitably increase by a large margin.

In addressing this issue, many international seminars have been held to discuss possible solutions to the problem. The 4th IPCC Report in 2007 (IPCC, 2007) and the Bali conference (Caillaud et al., 2012) marked a shift in research focus from looking for evidence of climate abnormalities to exploring measures to respond appropriately to global climate change. Given the current drive in both developed and developing nations to institute low-carbon economies even while coping with climate-related problems, it is particularly important to reduce the growth rate of greenhouse gas emissions through formulating targeted policies and taking effective measures. In fact, finding ways to effectively reduce greenhouse gas emissions has been the frontier research hotspot. One of the key issues is to quantitatively analyze the influencing factors of $\mathrm{CO}_{2}$ emissions, which is directly related to low-carbon policy formulation and the measures implemented.

At present, there are numerous studies on carbon emissions researched from a variety of angles (Moutinho et al., 2015; Karatayev and Clarke, 2016; Karatayev et al., 2016; Parkhomchik and Syrlybayeva, 2016; Schandl et al., 2016; Wang and Li, 2016; Zhang et al., 2016; Ramlall, 2017; Wang et al., 2017b; Zhao et al., 2017). Among other topics, researchers have looked at the quantity of greenhouse gas emissions through establishing various theoretical and mathematical models (Streets et al., 2001; Swan et al., 2013; Tang, 2014), researched the influencing factors of carbon emissions through various metering methods (Tang, 2014; Lin and Beidari, 2015; Zhao et al., 2017), and studied different kinds of controlling policies and measures (Aggarwal and Jain, 2016; Meyers et al., 2016). All of the research seeks to find a mechanism for maximum reduction of greenhouse gas emissions while minimizing any negative impacts on economy.

Studies on the influencing factors of $\mathrm{CO}_{2}$ emissions mainly use two main decomposition methods, one is structural decomposition analysis (SDA) and the other is index decomposition analysis (IDA). Compared to SDA, IDA has more advantages and is widely used. Popular IDA methods include the IPAT model (Wang et al., 2011a), Kaya identity (Ang, 2015), and the Laspeyres decomposition method (Lu et al., 2014). In recent years, numerous scholars have applied these methods to analyze energy-related carbon emissions on both large and small scales (York et al., 2003; Lu et al., 2014; Meyers et al., 2016; Zhao et al., 2017). Some scholars also improved the methods in order to clarify the influence mechanism of carbon emissions. For instance, based on extended Kaya identity, Ang (2004) made the Logarithmic Mean Divisia Index (LMDI) decomposition method, which is easier to use, more adaptable, and better suited to results interpretation. Hence, this approach is now widely applied in several fields, especially in energy-related carbon emissions in industrial sectors (Wang et al., 2011b; Ouyang and Lin, 2015; Li and Wang, 2016; Wang et al., 2017b; Zhao et al., 2017). The other preferred approach is the IPAT model, which is used to quantitatively evaluate environmental pressure through three influencing factors: population size, per capita affluence, and technological level (Wang et al., 2011a). A few authors have improved this model. Such as, York et al. (2003) developed the STIRPAT strategy, which considers the 
siders the individual influence of each factor on environment and eliminates the problem of the same proportional variation. This model is also widely used in energy-related carbon emissions. Lin et al. (2009) processed an empirical research based on the STIRPAT model and analyzed the environmental impact in China through five influencing factors, the result indicated that population was the largest potential driving factor on environmental variation. Wang et al. (2017a) used the extended STIRPAT model to examine the driving factors of energy-related carbon emissions from a regional perspective. Because energy-related carbon emissions is a key index for regional environment pressure, using the STIRPAT model to analyze the impact factors of carbon emissions is a good way to reflect regional environmental changes and can also provide constructive guidance for sustainable development of ecological environment.

Kazakhstan is a resource-rich country with abundant conventional energies, such as coal, oil and natural gas reserves (Ismailova, 2013). As an essential part of the Silk Road Economic Belt, it occupies an important position in the international energy market. In the first decade of the 21 st century, Kazakhstan ranked among the top three countries in the world for accelerated economic growth rates, due mainly to this country's energy production and consumption (Azatbek and Ramazanov, 2016; Kalyuzhnova and Patterson, 2016; Katenova and Nurmakhanova, 2017). It has gradually positioned itself as the economic engine in Central Asia.

However, along with the rapid economic development, Kazakhstan consumed more conventional energy and then exacerbated more $\mathrm{CO}_{2}$ emissions, with per capita $\mathrm{CO}_{2}$ emissions almost three times higher than the world average (Karatayev et al., 2016) (Figure 1). This has led to numerous energy-related environmental problems (Jiang and Feng, 2006; Xiong et al., 2015). The main cause underlying Kazakhstan's growing environmental problems is that their industry relies on low-grade coal as the primary raw material. In other words, the energy consumption structure of Kazakhstan is still dominated by coal, with the contribution rates of coal, oil and gas pegged at $63.02 \%, 19.76 \%$ and $17.21 \%$, respectively, to total $\mathrm{CO}_{2}$ emissions (Figure 2). The more energy consumed, the greater the amount of discharging $\mathrm{CO}_{2}$ emissions.

Kazakhstan, as one of the largest energy bases in the world, the previous studies on this country primarily focused on the national energy reserves and exploitation potentiality (Karatayev and Clarke, 2016; Parkhomchik and Syrlybayeva, 2016), energy geopolitics (Blank, 1995; Xu, 2010), energy multilateral cooperation (Bahgat, 2010; Movkebaeva, 2013) and energy production and exports (Yenikeyeff, 2008; Sarbassov et al., 2013). There was little interest in pursuing issues related to environmental pollution caused by energy consumption or the influence mechanism underscoring the country's rapid economic growth. Some scholars did research $\mathrm{CO}_{2}$ emissions solely from the macroscopic perspective, but stopped short of quantitatively analyzing the impact mechanism. To bridge this research gap, the present article will quantitatively analyze the energy-related $\mathrm{CO}_{2}$ emissions in Kazakhstan from 1992 to 2013, through applying the LMDI decomposition method and a modified STIRPAT model. The modified STIRPAT can better reflect the efficiency change of each factor to total $\mathrm{CO}_{2}$ emissions. Our purpose in conducting this study is to provide basic theoretical support for more optimized socio-economic development and efficient energy use, as well as to provide a reference for policy formulation to adjust energy structure and achieve low-carbon sustainable development in Kazakhstan. 


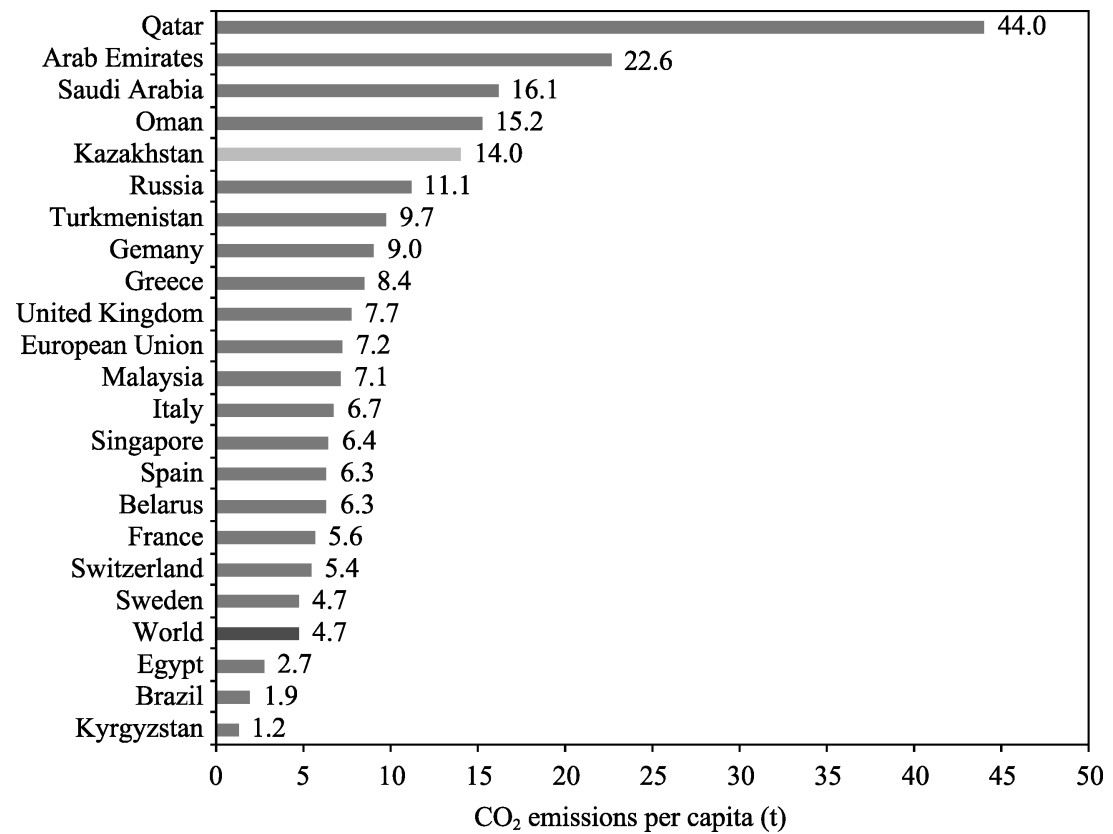

Figure 1 Per capita $\mathrm{CO}_{2}$ emissions rank in the world (Karatayev et al., 2016)

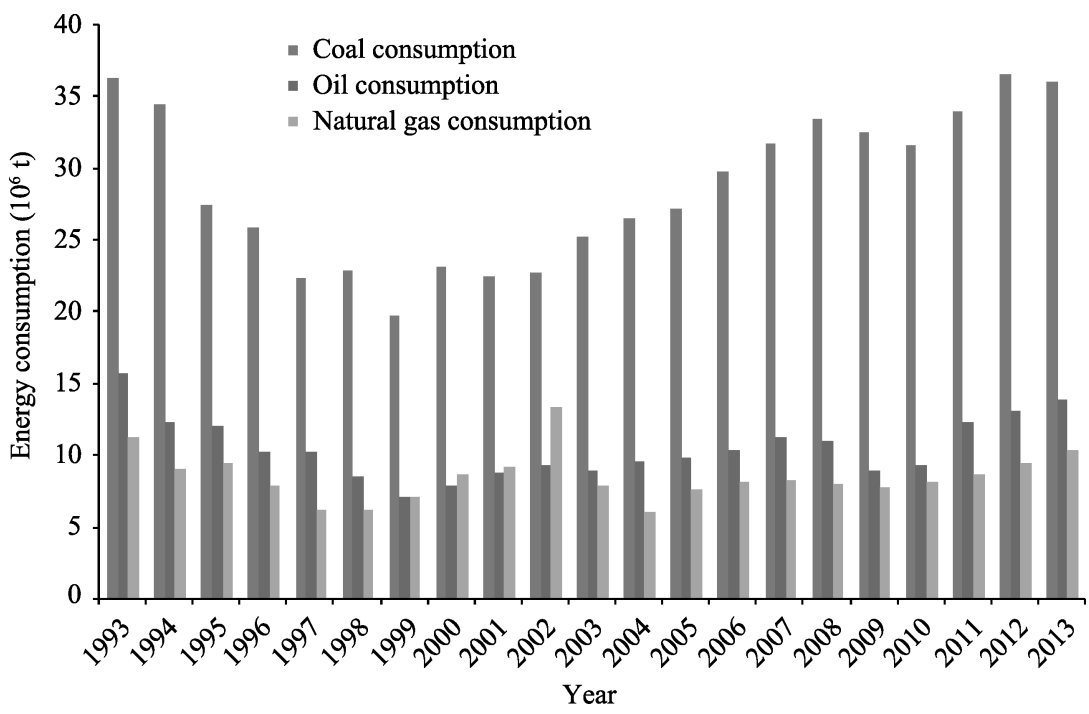

Figure 2 Consumptions of coal, oil and natural gas in Kazakhstan from 1993 to 2013

\section{Data and methodologies}

\subsection{Study area and data}

Kazakhstan is located in Central Asia with continental climate, to the north of Russia, to the east of China, to the west of Caspian, and to the south of Uzbekistan, Turkmenistan and Kyrgyzstan, it is the largest landlocked country in the world. This country is about $3000 \mathrm{~km}$ long from east to west, and $1700 \mathrm{~km}$ wide from north to south, with a territorial area of 271.73 ten thousand $\mathrm{km}^{2}$. Most of the territory is plain and lowland, and the east and south- 
east are Altai Mountains and Tianshan Mountains. Kazakhstan is rich in mineral resources, with the reputation of "energy and raw materials base" (Macgregor, 2017). The reserves and productions of oil and natural gas in Kazakhstan are just after Russia in the commonwealth of independent states, and oil and gas resources mainly distribute in Atyrau, Mangghsystau, Batysdy kazakstan, Aktube, Kyzylorda and Jambyl (Figure 3). Large oil fields concentrate in the western Mangrac peninsula and Caspian depression. Karakagana possesses the largest nature gas, and accounts for $70 \%$ of the total gas reserves in Kazakhstan. The storage of coal resource in Kazakhstan is third only to Russia and Ukraine, and accounts for $2.6 \%$ of the total coal reserves in the world (Karatayev et al., 2016). Coal mines are mainly distributed in Karaghandy, Pavlodar, Kostanay, Akmola and Shyghys kazakstan (Figure 3).

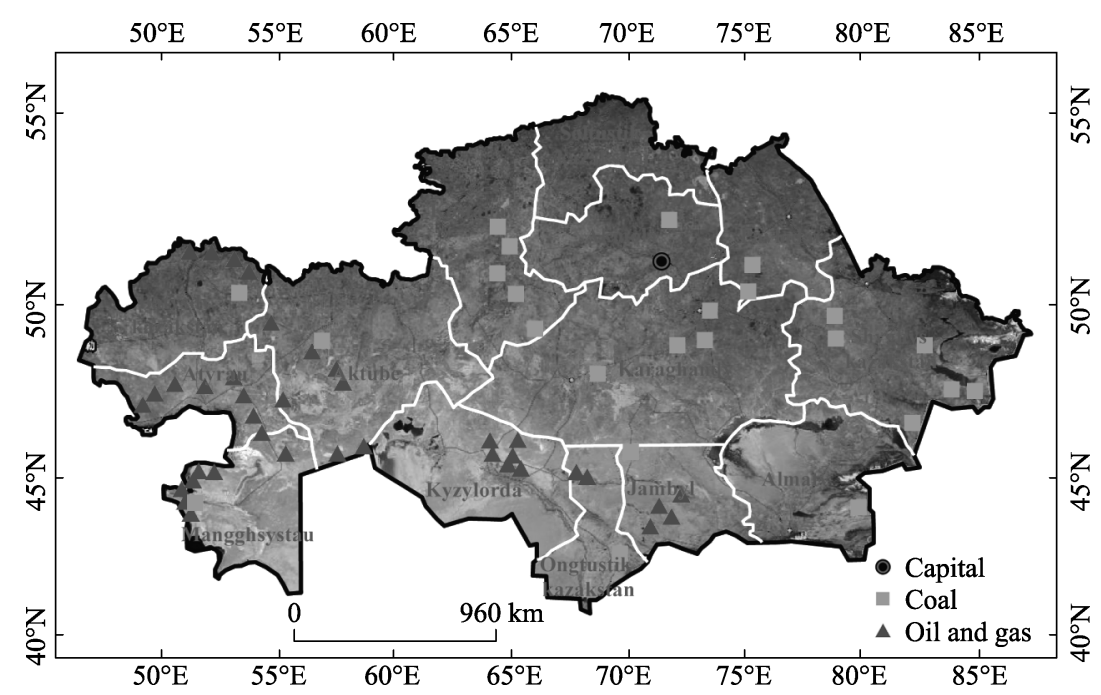

Figure 3 The spatial distribution of coal, oil and gas in Kazakhstan

The data for our research include carbon emissions, energy use, population and GDP, the study period is from 1992 to 2013 in Kazakhstan. The primary conventional energy resources include coal, oil and natural gas, and data on energy consumption of these three resources came directly from the Statistics Department of Kazakhstan (http://www.stat.gov.kz/). Energy-related carbon emissions data were downloaded from Carbon Dioxide Information Analysis Center (CDIAC) (http://cdiac.ess-dive.lbl.gov/), and converted to $\mathrm{CO}_{2}$ emissions simply multiply carbon emissions by 3.667 , because per unit carbon burning in oxygen can generate about 3.667 times carbon dioxide. The population and GDP data were extracted from World Bank (http://www.worldbank.org/). We converted the current GDP data to the 2005 constant price in order to eliminate the influence of currency inflation. The total energy use data came from World Bank (http://www.worldbank.org/).

\subsection{Methodologies}

\subsubsection{LMDI decomposition analysis}

The LMDI decomposition model shares many features with Kaya identity, and the latter was proposed by Yoichi Kaya, a Japanese scholar (Kaya, 1990). Kaya identity has the advantages of simple mathematical form, as it has no residuals and features strong explanatory power on the change in carbon emissions (Kaya, 1990; Kaya and Yokobori, 1997). In the structure, 
$\mathrm{CO}_{2}$ emissions are associated with population expansion, energy utilization and economic development level. The relationship among these factors based on Kaya identity can be written as:

$$
C=\sum_{j} C_{j}=\sum_{j} P \times \frac{G}{P} \times \frac{E}{G} \times \frac{C}{E}=\sum_{j} P \times A \times I \times S
$$

where $C$ indicates the total $\mathrm{CO}_{2}$ emissions ( $10^{6}$ tons), while $P, G$ and $E$ represent total population $\left(10^{4}\right.$ people), gross domestic product (GDP) at the 2005 constant price ( $10^{8}$ USD), and total energy consumption $\left(10^{4}\right.$ tce), respectively. $P, A, I$ and $S$ express the population effect, economic active effect, energy intensity effect and energy carbon structure effect, respectively.

According to Ang's research (2005), LMDI decomposition method is constructed based on Kaya identity, and includes two different calculation methods: additive LMDI method and multiplicative LMDI method (Wang et al., 2011b; Ang, 2015; Shao et al., 2016; Zhao et al., 2017). The results of these two methods are the same. This paper chose the additive LMDI method to research energy-related $\mathrm{CO}_{2}$ emissions in Kazakhstan as shown in the following equations:

$$
\begin{aligned}
\Delta C_{\text {tot }}=C^{T}-C^{0} & =\Delta C_{p o p}^{T}+\Delta C_{a c t}^{T}+\Delta C_{\text {int }}^{T}+\Delta C_{\text {str }}^{T} \\
\Delta C_{p o p}^{T} & =\sum_{j} \frac{C_{j}^{T}-C_{j}^{0}}{\ln C^{T}-\ln C^{0}} \ln \frac{P^{T}}{P^{0}} \\
\Delta C_{a c t}^{T} & =\sum_{j} \frac{C_{j}^{T}-C_{j}^{0}}{\ln C^{T}-\ln C^{0}} \ln \frac{G^{T}}{G^{0}} \\
\Delta C_{\text {int }}^{T} & =\sum_{j} \frac{C_{j}^{T}-C_{j}^{0}}{\ln C^{T}-\ln C^{0}} \ln \frac{I^{T}}{I^{0}} \\
\Delta C_{s t r}^{T} & =\sum_{j} \frac{C_{j}^{T}-C_{j}^{0}}{\ln C^{T}-\ln C^{0}} \ln \frac{S^{T}}{S^{0}}
\end{aligned}
$$

where $\triangle C_{\text {tot }}$ means the total increment of $\mathrm{CO}_{2}$ emissions during the study period, and $\triangle C_{p o p}, \triangle C_{a c t}, \triangle C_{i n t}$ and $\triangle C_{s t r}$ are the amounts of variation in $\mathrm{CO}_{2}$ emissions from four influencing factors of population effect, economic active effect, energy intensity effect and energy carbon structure effect, respectively.

\subsubsection{Modified STIRPAT model construction}

The initial environmental pressure model is the IPAT model proposed by Ehrlich and Holdren (1974) to measure the impact of socio-economic change on environmental pressure. In the acronym IPAT, $I$ represents environmental impact (Impact), $P$ is population size (Population), $A$ denotes per capita affluence (Affluence), and $T$ expresses technology level (Technology). In the traditional IPAT model, environmental pressure is driven by three factors: population, affluence and technology, this model provides very simplistic and effective analysis. However, its biggest defect is that it assumes the elasticity change rate is uniform for population, affluence and technology in relation to environment. That is to say, when any influencing factor increases or decreases by $1 \%$, the environmental pressure likewise gives a $1 \%$ variation. 
In order to make up for this defect, York et al. (2003) constructed a random STIRPAT model based on the IPAT approach. The model equation can be expressed as:

$$
I=a P^{b} A^{c} T^{d} e
$$

where the implications of $I, P, A$ and $T$ are in keeping with the IPAT model, meaning that they respectively stand for environmental impact, population size, per capita affluence and technology level. Thus, $a$ represents the fit coefficient of the model; $b, c$ and $d$ are the indices of each explanatory variable; and $e$ denotes the error term generated in the model construction. Introducing the indices of $b, c$ and $d$ can better compensate for the defect of proportional changes between the explained variable $I$ and each driving factor. In other words, this model can be applied to analyze the unconstrained effect of independent variables for environmental pressure (Liu et al., 2015; Zhang and Liu, 2015).

The STIRPAT model is a nonlinear approach featuring multiple independent variables. In order to eliminate the larger fluctuant tendency of time series and to overcome the heteroscedasticity of the sequence, we first need to perform logarithmic processing on the original data. Hence, we take the logarithmic transformation of the Equation (7) and obtain the following model:

$$
\ln I=\ln a+b \ln P+c \ln A+d \ln T+\ln e
$$

Similarly, we use this equation to describe the influence mechanism of energy-related $\mathrm{CO}_{2}$ emissions. In our research, we use total $\mathrm{CO}_{2}$ emissions to represent the environmental impact, while the economic development level represents the affluence and the energy intensity represents the technology level. In addition, we expanded Equation (8) to add the influencing factor of energy carbon structure in order to examine the impact of energy structure change on $\mathrm{CO}_{2}$ emissions. However, if more renewable energy than traditional energy were to be used, the energy structure would improve and $\mathrm{CO}_{2}$ emissions would decrease. Therefore, Equation (9) can be rewritten as:

$$
\ln C=a+b \ln P+c \ln A+d \ln I+e \ln S+f
$$

where $C$ represents total $\mathrm{CO}_{2}$ emissions; $P$ represents population size (i.e., total population in Kazakhstan, $10^{4}$ people); $A$ represents economic development level as expressed by per capita GDP (USD/people, with the GDP converted to the 2005 constant price); I represents energy intensity, meaning energy consumption per GDP (tce $/ 10^{4} \mathrm{USD}$, where energy consumption is converted to ton of standard coal equivalent); and $S$ represents the energy structure indicated by $\mathrm{CO}_{2}$ emissions per energy consumption ( $\left.\mathrm{t} / \mathrm{tce}\right)$. Furthermore, $a$ is the constant term, $b, c, d$ and $e$ denote elasticity coefficients of the explanatory variables to the explained variable, and $f$ shows the error term. When each of $P, A, I$ and $S$ increases $1 \%, \mathrm{CO}_{2}$ emissions correspondingly increase $b \%, c \%, d \%$ and $e \%$, respectively.

\section{Results and analysis}

\subsection{Trajectory of $\mathrm{CO}_{2}$ emissions in Kazakhstan}

The trajectories of $\mathrm{CO}_{2}$ emissions and per capita emissions assumed similar variation trends in Kazakhstan during the study period (Figure 4). Both of them declined first and then rose except the year of 2008 and 2009. In other words, they displayed U-shaped curves from 1992 to 2013, with 1999 marking the decisive turning point. 
In general terms, $\mathrm{CO}_{2}$ emissions within the study region can be divided into two periods: 1992-1999 and 2000-2013. During the first stage of 1992 to 1999, $\mathrm{CO}_{2}$ emissions and per capita emissions decreased swiftly at an average annual growth rate of $-11.3 \%$ and $-10.1 \%$ respectively, due primarily to the disintegration of the Soviet Union in 1991. At the beginning of independence, Kazakhstan faced serious political and economic crises that were so profound that they prompted many people to emigrate to other countries (Rowland, 2001). This led to a sudden decrease in population of 1.51 million, or an approximate $9 \%$ reduction. The gross domestic product (GDP) correspondingly diminished by 105.8 billion USD, or approximately $25 \%$. Amidst the poorly-performing economy and production difficulties, energy use also decreased $43 \mathrm{Mt}$ (million tons), marking an astonishing 54\% reduction (Figure 5). Making matters worse was the 1998 Asian financial crisis (Mao, 2014). All of which led to $\mathrm{CO}_{2}$ emissions rapidly decrease in this stage.

The second stage is from 2000 to 2013, during which $\mathrm{CO}_{2}$ emissions increased except in 1998, 1999 and 2012, with 2000 to 2007 seeing the fastest increase. Overall, $\mathrm{CO}_{2}$ emissions and per capita emissions increased $104 \mathrm{Mt}$ and $6.42 \mathrm{t}$ /people, with the average annual growth rates of $9.46 \%$ and $8.84 \%$, respectively. Emissions fell again from 1998 to 1999 because of the global financial crisis happened in 1998 (Ruziev and Majidov, 2013), as the economic slump weakened the growth of energy consumption. Subsequently, $\mathrm{CO}_{2}$ emissions greatly reduced over those two years. After then, with drastic improvement in the international macro economy and financial environment, $\mathrm{CO}_{2}$ emissions again increased, but at a smaller rate. The European debt crisis during the first half of 2012 (Mao, 2014) also led to slight declines in $\mathrm{CO}_{2}$ and per capita emissions.

Carbon emissions intensity is described as $\mathrm{CO}_{2}$ emissions per unit of GDP growth. Interestingly, and despite the country's emergence as an energy powerhouse, the carbon emissions intensity of Kazakhstan nearly charted a decrease for the period of 1992 to 2013. It was also affected by economic growth and took a similar course in carbon emissions from 1992 to 1999 and 2008 to 2013. However, it veered from that course between 2000 and 2007, when the economy and energy consumption rapidly increased while carbon emissions intensity decreased. This can be interpreted as the GDP increasing at a far greater rate than energy consumption, thus increasing total $\mathrm{CO}_{2}$ emissions but decreasing $\mathrm{CO}_{2}$ emissions per unit of GDP.

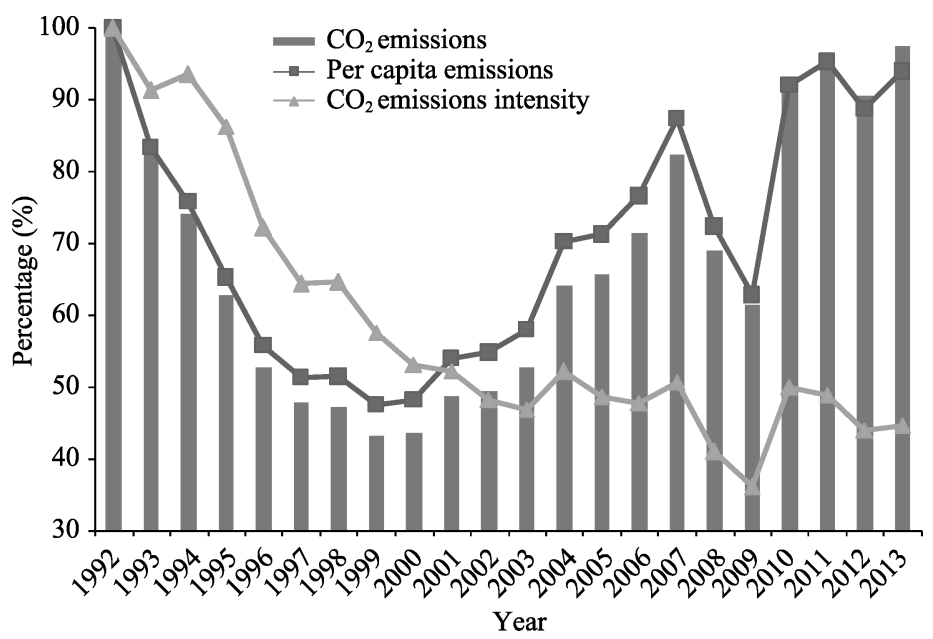

Figure 4 Trajectories of $\mathrm{CO}_{2}$ emissions, per capita emissions and carbon emissions intensity in Kazakhstan (using 1992 as the baseline year) 


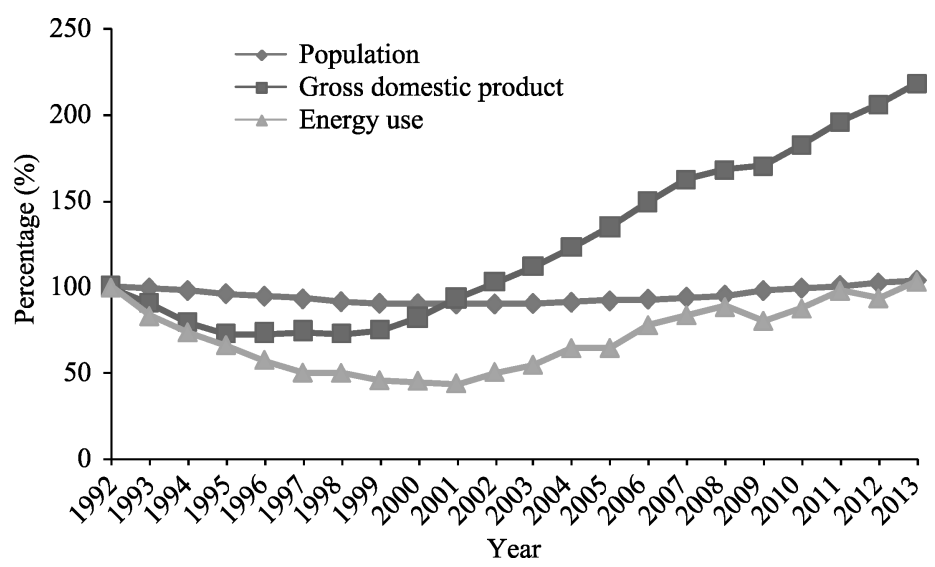

Figure 5 Change rates of population, GDP and energy use from 1992 to 2013 in Kazakhstan (using 1992 as the baseline year)

\subsection{Additive LMDI decomposition of $\mathrm{CO}_{2}$ emissions}

\subsubsection{The effect and contribution rate of decomposition factors}

In order to further explore the intrinsic influence mechanism in $\mathrm{CO}_{2}$ emissions and gauge the impact of each influencing factor in the two stages delineated above, we applied the additive LMDI method to decompose the total $\mathrm{CO}_{2}$ emissions into four influencing factors: population effect, economic active effect, energy intensity effect and energy carbon structure effect. Then we received the variation and contribution rate of each factor for each year. The decomposition results are shown in Table 1 and Figure 6.

In the first stage (1992 to 1999), total $\mathrm{CO}_{2}$ emissions posted a $-153.33 \mathrm{Mt}$ decrease. All the factors displayed negative effects, especially the main ones of energy intensity and economic activity. Specifically, energy intensity resulted in $-78.73 \mathrm{Mt} \mathrm{CO}_{2}$ emissions, and economic activity gave rise to $-48.38 \mathrm{Mt} \mathrm{CO}_{2}$ emissions, both of which were the primary contributors to total $\mathrm{CO}_{2}$ emissions continuous decline, the contribution rates were $51.35 \%$ and $31.55 \%$, respectively. The lowest contributor was the energy carbon structure effect, which led to only $-10.4 \mathrm{Mt} \mathrm{CO}_{2}$ emissions, for a contribution rate of just $6.78 \%$. The main reason underlying these changes was social unrest and economic recession affected by the collapse of the Soviet Union and Asian financial crisis, leading to a decline in people's living standards and in energy production and consumption, and then reduced $\mathrm{CO}_{2}$ emissions.

In the second stage (2000 to 2013), total $\mathrm{CO}_{2}$ emissions increased $146.4 \mathrm{Mt}$, but still remained lower than the decrease amount in the first stage. For each factors contribution, economic activity in the second stage produced $159.24 \mathrm{Mt} \mathrm{CO}_{2}$ emissions with a contribution rate of $108.77 \%$, it is far beyond those of the first stage. Within a stabilized political and economic environment, the population also increased, adding a $\mathrm{CO}_{2}$ emissions contribution rate of $18.91 \%$. Furthermore, energy intensity produced $-32.17 \mathrm{Mt} \mathrm{CO}_{2}$ emissions and the contribution rate was $-21.97 \%$, the negative contribution is less than the first stage, because energy consumption of per unit GDP was less in stage two. Energy carbon structure effect resulted in $-8.63 \mathrm{Mt} \mathrm{CO}_{2}$ emissions for a contribution rate of $-5.71 \%$, the negative effect was weaker compared to the first stage, this indicated that Kazakhstan still mainly relied on coal consumption to pursue rapid economic growth, so the energy structure was not opti- 
mized in this stage. In addition, European debt crisis and global financial crisis also played a large role in changes to energy carbon structure and $\mathrm{CO}_{2}$ emissions.

Table 1 Contribution of each influencing factor of $\mathrm{CO}_{2}$ emissions in Kazakhstan $\left(10^{6} \mathrm{t}\right)$

\begin{tabular}{|c|c|c|c|c|c|}
\hline Time Period & $\triangle \mathrm{C}_{\mathrm{pop}}$ & $\triangle \mathrm{C}_{\mathrm{act}}$ & $\triangle \mathrm{C}_{\text {int }}$ & $\triangle \mathrm{C}_{\mathrm{str}}$ & $\triangle \mathrm{C}_{\text {tot }}$ \\
\hline 1992-1993 & -1.63 & -22.12 & -21.42 & -0.90 & -46.06 \\
\hline 1993-1994 & -3.07 & -25.45 & 2.87 & 2.15 & -23.50 \\
\hline 1994-1995 & -3.23 & -12.55 & -3.94 & -11.01 & -30.73 \\
\hline 1995-1996 & -2.36 & 3.13 & -22.80 & -4.89 & -26.91 \\
\hline 1996-1997 & -2.15 & 4.44 & -21.09 & 5.63 & -13.17 \\
\hline 1997-1998 & -2.22 & -0.25 & 1.95 & -1.63 & -2.14 \\
\hline 1998-1999 & -1.16 & 4.41 & -14.31 & 0.24 & -10.83 \\
\hline 1992-1999 & -15.82 & -48.38 & -78.73 & -10.40 & -153.33 \\
\hline 1999-2000 & -0.35 & 11.32 & -11.76 & 2.40 & 1.61 \\
\hline $2000-2001$ & -0.21 & 16.02 & -19.86 & 17.80 & 13.75 \\
\hline $2001-2002$ & 0.01 & 12.41 & 6.20 & -16.73 & 1.88 \\
\hline $2002-2003$ & 0.46 & 11.80 & -1.05 & -2.74 & 8.47 \\
\hline 2003-2004 & 1.09 & 13.31 & 11.38 & 5.06 & 30.84 \\
\hline $2004-2005$ & 1.56 & 14.66 & -15.91 & 3.97 & 4.28 \\
\hline $2005-2006$ & 1.96 & 16.84 & 16.04 & -19.53 & 15.30 \\
\hline $2006-2007$ & 2.37 & 15.29 & -2.52 & 14.58 & 29.71 \\
\hline $2007-2008$ & 2.48 & 4.13 & 4.70 & -47.47 & -36.15 \\
\hline 2008-2009 & 4.64 & -2.54 & -18.96 & -3.43 & -20.29 \\
\hline 2009-2010 & 2.88 & 11.47 & 3.00 & 63.36 & 80.71 \\
\hline 2010-2011 & 3.61 & 14.67 & 10.11 & -15.89 & 12.50 \\
\hline 2011-2012 & 3.55 & 8.74 & -23.84 & -2.84 & -14.40 \\
\hline $2012-2013$ & 3.66 & 11.12 & 10.29 & -6.90 & 18.18 \\
\hline $2000-2013$ & 27.69 & 159.24 & -32.17 & -8.36 & 146.40 \\
\hline
\end{tabular}

Overall, the total increment of $\mathrm{CO}_{2}$ emissions increased during the study period, but the variation trend was uneven, especially after 2008. This is impacted not only by international market, but also by local economic activity. More remarkably, $\mathrm{CO}_{2}$ emissions continuously increased during 2000 to 2007 . From the perspective of each influencing factor, to be specific, economic activity effectively produced $110.86 \mathrm{Mt} \mathrm{CO}_{2}$ emissions, with a contribution rate of $43.92 \%$. Population was the other driving force, as it led to $11.87 \mathrm{Mt} \mathrm{CO}_{2}$ emissions, and the contribution rate was $4.70 \%$. Meanwhile, population decreased first and then increased in two stages respectively, this repositioned $\mathrm{CO}_{2}$ emissions from a negative effect to a positive one, along with changes in population scale from negative growth prior to 1999 to higher positive growth post-2000.

Moreover, energy intensity was the main inhibiting factor to reduce $\mathrm{CO}_{2}$ emissions. The negative effect was obvious in the first stage but changed in the second stage, causing $-110.90 \mathrm{Mt} \mathrm{CO}_{2}$ emissions with a contribution rate of $-43.94 \%$. Energy carbon structure was the other inhibiting factor with a significant change in amplitude, especially in 2008 and 2010. It resulted in $-18.76 \mathrm{Mt} \mathrm{CO}_{2}$ emissions, with a contribution rate of $-7.43 \%$. Given that coal remains the primary energy source in Kazakhstan, a sluggish energy consumption structure 
will be the main reason for the lack of a dramatic reduction in $\mathrm{CO}_{2}$ emissions (Figure 6).

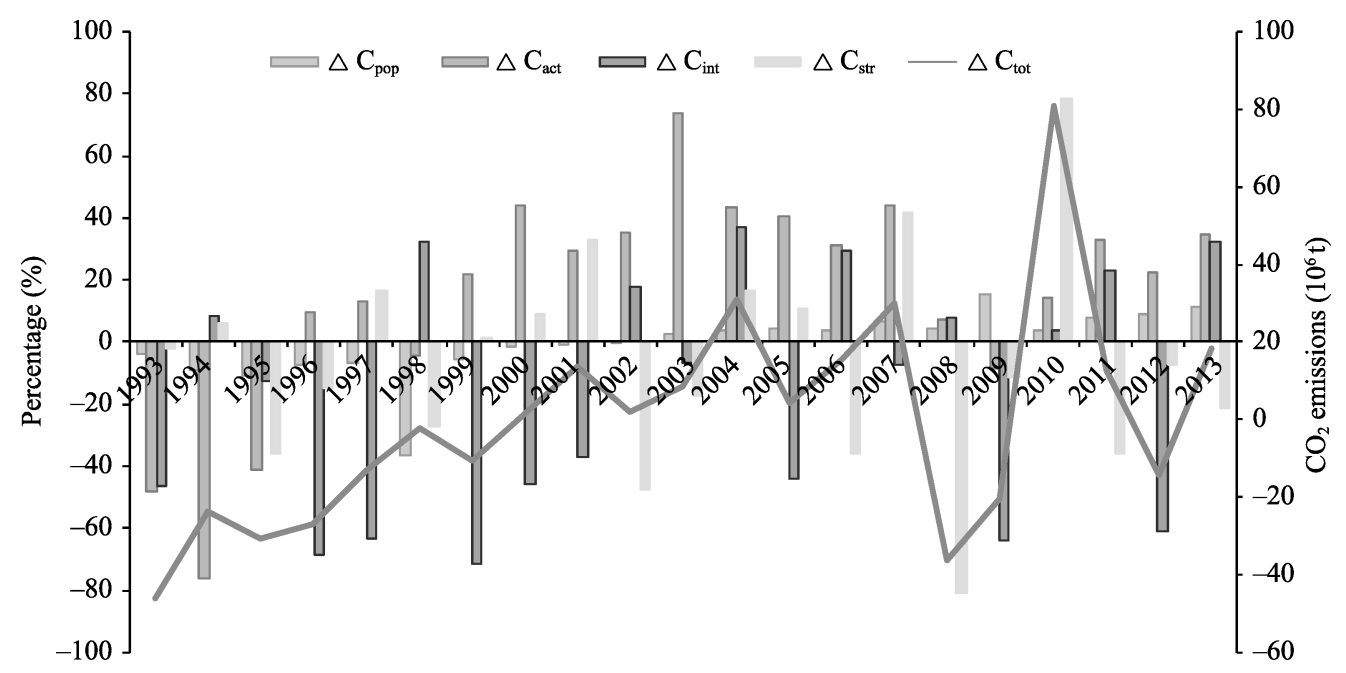

Figure 6 Additive LMDI decomposition of $\mathrm{CO}_{2}$ emissions in Kazakhstan

\subsubsection{Cumulative effect of each factor in $\mathrm{CO}_{2}$ emissions}

The cumulative effects were calculated to further understand the change of $\mathrm{CO}_{2}$ emissions in the study period (Figure 7). Under the sluggish economy after independence, the cumulative emissions of the economic activity effect appeared as negative growth during the phase of 1992-2002, with the largest negative growth year in 1996. After 2002, the cumulative effect was positive and increased rapidly other than 2008, which was influenced by global financial crisis. Overall, economic activity is the main driving factor to increase $\mathrm{CO}_{2}$ emissions. The cumulative emissions of the energy intensity effect were always negative during the study period and in fact underwent a swift decrease from 1992 to 2001 as a consequence of lower energy consumption, after 2002, the cumulative effect showed almost no obvious change, which indicated that energy use efficiency did not improve by much during this period. The cumulative emissions of the population effect were weak due to the population emigration which occurred after independence, and cumulative emissions were negative until 2010. The cumulative emissions of energy carbon structure effect were almost negative and showed a weak change in every year except 2008 and 2009, which were strongly affected by global financial crisis. Because Kazakhstan mainly depends on coal, oil and natural

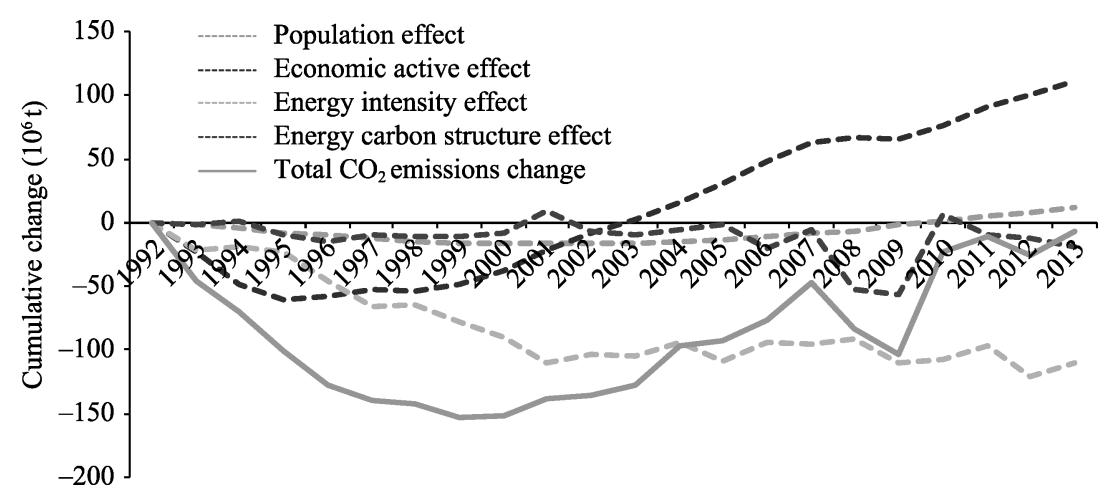

Figure 7 Cumulative effect of each factor in $\mathrm{CO}_{2}$ emissions based on additive LMDI decomposition 
gas to develop its economy, global market economy has influenced energy production and exportation, and further influenced energy structure and $\mathrm{CO}_{2}$ emissions. The total cumulative emissions until the end year were still lower than the baseline year of 1992, which points to some energy policies taking place as well as $\mathrm{CO}_{2}$ emissions being tied to economic development.

\subsection{The response between energy-related $\mathrm{CO}_{2}$ emissions and impact factors}

The LMDI method can analyze the main effect and contribution of each influencing factor in relation to $\mathrm{CO}_{2}$ emissions in Kazakhstan from a macroscopic perspective. However, the method cannot fully describe carbon emissions variations when one impact factor changes. In other words, it cannot depict the changing response between energy consumption carbon emissions and the driving factors. Based on this defect, we constructed a modified STIRPAT model to describe the changing response relationship between $\mathrm{CO}_{2}$ emissions and its impact factors in Kazakhstan.

\subsubsection{Stationarity test}

Before establishing the STIRPAT model, the stationarity of each variable must undergo a unit root test. In this paper, we applied the ADF (Augmented Dickey-Fuller) statistic to process the unit root test for the five variables, where $\ln C$ is the explained variable and $\ln P$, $\ln A, \ln I$ and $\ln S$ are the explanatory variables. The original hypothesis of the ADF test is that the variable has a unit root. If the ADF test value is smaller than the significant level, we reject the original hypothesis and assume that the data is stationary. Otherwise, the original hypothesis can be accepted. If the original sequence indicates non-stationary status, we need to process the first-order difference. Furthermore, if the first-order difference result is still non-stationary, we need to process the second-order difference. The results are shown in Table 2.

Table 2 Results of ADF unit root test

\begin{tabular}{|c|c|c|c|c|c|c|c|}
\hline \multirow{2}{*}{ Variables } & \multirow{2}{*}{ Test type } & \multirow{2}{*}{ ADF test value } & \multicolumn{3}{|c|}{ Significant level } & \multirow{2}{*}{ P-value } & \multirow{2}{*}{ Conclusion } \\
\hline & & & $1 \%$ & $5 \%$ & $10 \%$ & & \\
\hline $\ln C$ & $(\mathrm{c}, \mathrm{t}, 0)$ & -2.58 & -4.47 & -3.65 & -3.26 & 0.29 & Non-stationary \\
\hline $\mathrm{D} \operatorname{lnC}$ & $(\mathrm{c}, \mathrm{t}, 1)$ & -4.17 & -4.53 & -3.67 & -3.28 & 0.02 & Non-stationary \\
\hline $\mathrm{DD} \ln \mathrm{C}$ & $(0,0,1)$ & -8.10 & -2.70 & -1.96 & -1.61 & 0.00 & Stationary \\
\hline $\ln P$ & $(\mathrm{c}, 0,3)$ & -2.16 & -3.86 & -3.04 & -2.66 & 0.23 & Non-stationary \\
\hline $\mathrm{D} \ln \mathrm{P}$ & $(\mathrm{c}, \mathrm{t}, 0)$ & -3.09 & -4.50 & -3.66 & -3.27 & 0.14 & Non-stationary \\
\hline $\mathrm{DD} \ln \mathrm{P}$ & $(\mathrm{c}, 0,0)$ & -5.42 & -3.83 & -3.03 & -2.66 & 0.00 & Stationary \\
\hline $\ln A$ & $(\mathrm{c}, \mathrm{t}, 4)$ & -3.41 & -4.62 & -3.71 & -3.30 & 0.08 & Non-stationary \\
\hline $\mathrm{D} \ln \mathrm{A}$ & $(\mathrm{c}, 0,2)$ & -2.83 & -3.86 & -3.04 & -2.66 & 0.07 & Non-stationary \\
\hline $\mathrm{DD} \ln \mathrm{A}$ & $(0.0 .1)$ & -4.69 & -2.70 & -1.96 & -1.61 & 0.00 & Stationary \\
\hline $\ln I$ & $(0,0,0)$ & -2.31 & -2.68 & -1.96 & -1.61 & 0.02 & Non-stationary \\
\hline DlnI & $(0,0,0)$ & -4.09 & -2.69 & -1.96 & -1.61 & 0.00 & Stationary \\
\hline DDlnI & $(\mathrm{t}, 0,2)$ & -5.55 & -3.89 & -3.05 & -2.67 & 0.00 & Stationary \\
\hline $\ln S$ & $(\mathrm{t}, 0,0)$ & -3.48 & -3.79 & -3.01 & -2.65 & 0.02 & Non-stationary \\
\hline $\mathrm{D} \ln \mathrm{S}$ & $(0,0,1)$ & -5.01 & -2.69 & -1.96 & -1.61 & 0.00 & Stationary \\
\hline $\mathrm{DD} \ln \mathrm{S}$ & $(0,0,4)$ & -3.92 & -2.73 & -1.97 & -1.61 & 0.00 & Stationary \\
\hline
\end{tabular}

Note: In the test type $(\mathrm{c}, \mathrm{t}, \mathrm{k}), \mathrm{c}$ is the constant term, $\mathrm{t}$ is the trend term and $\mathrm{k}$ is the lag order, as determined by AIC criterion. The bold numbers represent the ADF test values through the significant critical level. 
From Table 2, we can see that the ADF tests of the second-order difference of the five variables are all through the $1 \%$ significant level. This indicates the variables have no unit root and have achieved stationary status. The variables are the same order and single integer sequences, which is the premise for constructing the model.

\subsubsection{Multiple collinearity diagnosis}

In order to correctly estimate the parameters of the model, we need to verify whether multiple collinear problems exist among different variables. Hence, a multiple collinearity diagnosis must be performed for each variable. The diagnostic results are presented in Table 3.

Table 3 Results of multiple collinearity diagnosis of each variable

\begin{tabular}{ccccc}
\hline Variable & Tolerance & Variance inflation factor (VIF) & Eigenvalue & Condition index (CI) \\
\hline Constant & - & - & 4.984 & 1.000 \\
$\ln P$ & 0.287 & 3.488 & 0.011 & 20.940 \\
$\ln A$ & 0.132 & 7.588 & 0.004 & 35.381 \\
$\ln I$ & 0.163 & 6.134 & 0.000 & 124.826 \\
$\ln S$ & 0.928 & 1.077 & $5.998 \mathrm{E}-06$ & 911.590 \\
\hline
\end{tabular}

Variance inflation factor (VIF) is the reciprocal of tolerance. In general, if the Tolerance of the explanatory variable is less than 0.1 or the VIF is more than 10 , the multicollinearity phenomenon may exist among the variables. Table 3 shows that multicollinearity may not exist among variables from the perspective of Tolerance and VIF. However, in statistics, if the Eigenvalue is close to 0 or the CI value is greater than 30 , this indicates that multicollinearity might exist among variables. From Table 3 we also see the Eigenvalue values of all explanatory variables are close to 0 and the CI values of $\ln A, \ln I$ and $\ln S$ are all greater than 30. Given this situation, it is possible that multicollinearity exists among explanatory variables and the explained variable from the angles of Eigenvalue and CI. Hence, it is not suitable to use the ordinary least square (OLS) method for unbiased estimation.

\subsubsection{Ridge regression analysis}

In order to overcome the influence of multicollinearity among variables, methods such as gradual regression, principal component analysis or ridge regression can be used for model fitting to solve this problem. In this paper, we chose ridge regression to effectively solve the multiple collinear problems. Ridge regression estimation was proposed by Hoerl and Kennard (1970). It is a biased estimate method, improved by the least squares estimation. The ridge regression results are shown in Figure 8 and Table 4.

Ridge regression is performed by adding a set of normal numbers (i.e., ridge parameter $\mathrm{K}$ ) to the diagonal of a standardized matrix of explanatory variables, which would make the inverse operation relatively stable (Marquardt and Snee, 1975). If the ridge parameter K is chosen reasonably, the results of ridge regression will greatly reduce the variance of parameter estimation under minor unbiasedness. The change range of $\mathrm{K}$ value is from 0 to 1 . From Figure 8, we can see that when $\mathrm{k}=0.2$, the determination coefficient $\mathrm{R}^{2}$ is 0.9094 and that the change trend of the regression coefficient of each variable gradually towards stability. Therefore, we get a normalized ridge regression equation when $\mathrm{k}=0.2$. However, if we want to analyze the elastic coefficient between $\mathrm{CO}_{2}$ emissions and each influencing factor, we need to further restore the normalized ridge regression to its corresponding non- 


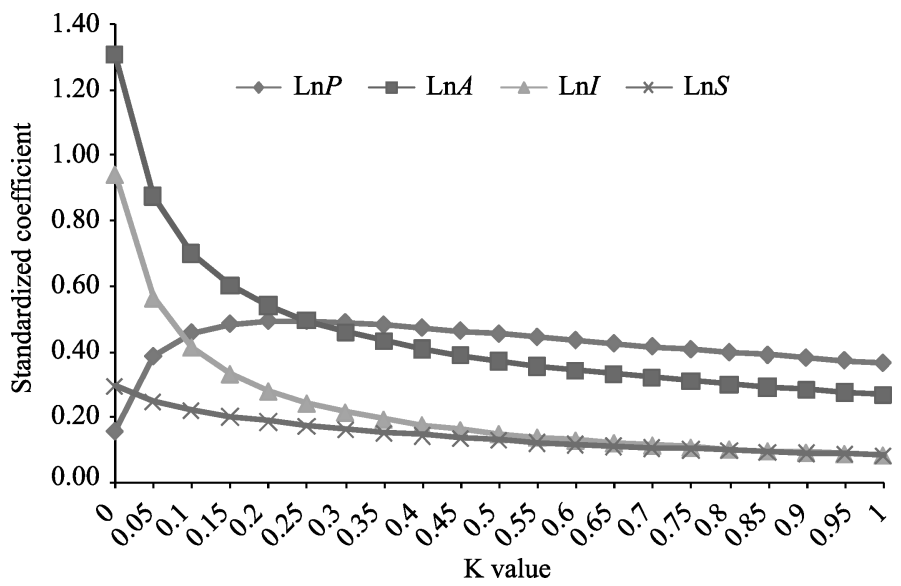

Figure 8 Variation trends of standardized coefficients of the explanatory variations along with K value change

Table 4 Ridge regression results of energy-related $\mathrm{CO}_{2}$ emissions in Kazakhstan

\begin{tabular}{cccccc}
\hline Variable & Parameter & Standard error & Standardized coefficient & t Statistics & p-Value \\
\hline Ln $P$ & 3.1289 & 0.3801 & 0.4934 & 8.2320 & 0.0000 \\
Ln $A$ & 0.4138 & 0.0457 & 0.5403 & 9.0562 & 0.0000 \\
Ln $I$ & 0.2965 & 0.0633 & 0.2793 & 4.6852 & 0.0002 \\
Ln $S$ & 0.6323 & 0.2086 & 0.1862 & 3.0307 & 0.0075 \\
Constant & -22.6320 & 2.7889 & 0.0000 & -8.1150 & 0.0000 \\
& $\mathrm{R}^{2}=0.9094$ & F Statistics $=42.6392$ & Sig.F $=0.0001$ & \\
\hline
\end{tabular}

standardized ridge regression equation. The transformation results are shown in Table 4, and we can see that all the variables passed the significant test. Therefore, the modified STIRPAT model can be written as Equation (10) based on the fitting parameters of ridge regression estimation.

$$
\ln C=-22.63+3.13 \ln P+0.41 \ln A+0.30 \ln I+0.63 \ln S
$$

Equation (10) can be used to analyze the response relationship between energy-related $\mathrm{CO}_{2}$ emissions and each influencing factor. From the elastic coefficients of the model, we can see that population size has the greatest influence on increase $\mathrm{CO}_{2}$ emissions: if the population increases $1 \%, \mathrm{CO}_{2}$ emissions will increase $3.13 \%$. However, because of the collapse of the Soviet Union, along with social unrest and poor living conditions, the population size of Kazakhstan decreased from 1992 to 1999 due to mass emigration. Following the social recovery, the population began slowly to increase at a rate of $3.62 \%$ (Figure $9 \mathrm{~b}$ ) or by 596,180 people over the 1992 population statistics. Thus, the sudden decrease followed by a slow increase limited a large contribution to $\mathrm{CO}_{2}$ emissions.

The elastic coefficient of economic activity is 0.41 , which indicates a $1 \%$ growth of economy and $0.41 \%$ increase of $\mathrm{CO}_{2}$ emissions. On the whole, Kazakhstan's economy experienced a swift increase after economic reform. In fact, it increased almost $110.62 \%$ between 1992 and 2013 (Figure 9c), mainly through rises in energy consumption and energy exportation. Therefore, economic growth is the main driving factor to prompt a rapid increase in $\mathrm{CO}_{2}$ emissions.

In reference to energy intensity, the elastic coefficient is 0.30 , which indicates that if en- 
ergy intensity increases $1 \%, \mathrm{CO}_{2}$ emissions will increase $0.30 \%$. In other words, the change in energy intensity is positively correlated to $\mathrm{CO}_{2}$ emissions. So, if energy intensity decreases $1 \%, \mathrm{CO}_{2}$ emissions will decrease $0.30 \%$. Figure $9 \mathrm{~d}$ illustrates the decrease in energy intensity from 1992 to 2013, in detail, it decreased -9.80 tce/10 4 USD in 2013, which was a sharp contrast to 1992 with the decrease rate of $-52.6 \%$. The change in energy intensity was not stable, with a significant decrease from 1992 to 1999 (due to the economic recession) and a weak decrease from 2000 to 2013 . Generally, energy intensity was an inhibiting factor to $\mathrm{CO}_{2}$ emissions, but the energy use efficiency was relatively low.

Regarding the energy carbon structure effect, the elastic coefficient is 0.63 , which indicates that if energy carbon structure increases $1 \%, \mathrm{CO}_{2}$ emissions will increase $0.63 \%$. Similar to energy intensity change, this factor also presented a fluctuating declining trend from 1992 to 2013 (Figure 9e), that means energy carbon structure decreases $1 \%, \mathrm{CO}_{2}$ emissions reduce $0.63 \%$. Compared to energy intensity, the reducing proportion of energy carbon structure is greater, so adjusting the energy use structure and developing new energies can be a more effective way to reduce $\mathrm{CO}_{2}$ emissions in Kazakhstan.
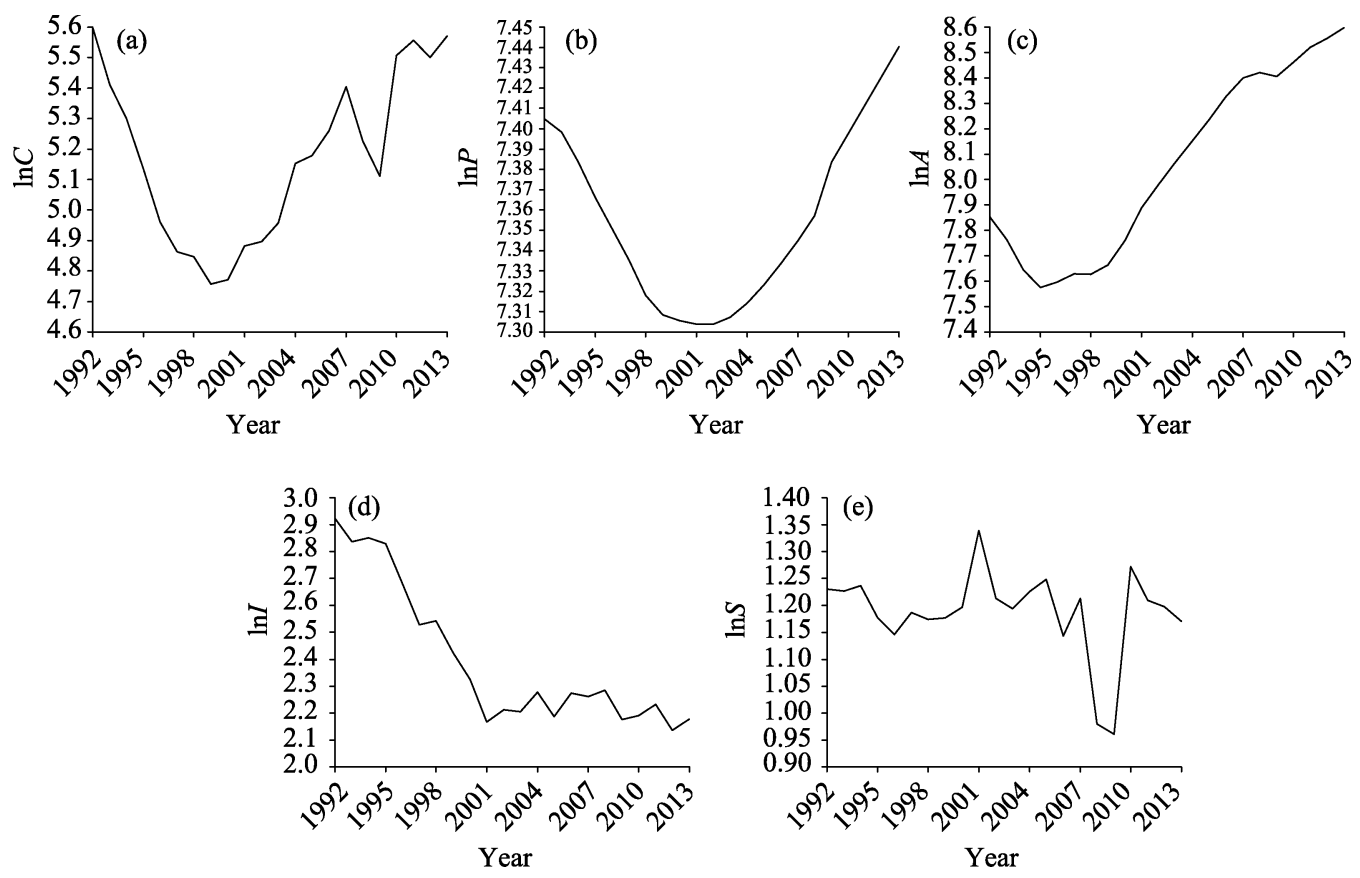

Figure 9 The changing trend of each index by logarithm disposition. (a) total $\mathrm{CO}_{2}$ emissions; (b) population size; (c) economic growth; (d) energy intensity; (e) energy carbon structure

\section{Conclusions and policy suggestions}

\subsection{Conclusions}

$\mathrm{CO}_{2}$ emissions experienced a swift decline from 1992 to 1999 due mainly to the collapse of the Soviet Union, which led to a recession in social and economic development. Following the subsequent economic reform, $\mathrm{CO}_{2}$ emissions gradually increased after 2000 together with economic recovery. Both $\mathrm{CO}_{2}$ emissions and per capita emissions displayed U-shaped curves from 1992 to 2013, while carbon emissions intensity constantly decreased during the 
study period.

According to LMDI decomposition results, economic activity and population took the positive effects to increase $\mathrm{CO}_{2}$ emissions. Economic activity produced $110.86 \mathrm{Mt} \mathrm{CO}_{2}$ emissions and population expansion led to $11.87 \mathrm{Mt} \mathrm{CO}_{2}$ emissions, the contribution rates of these two factors were $43.92 \%$ and $4.70 \%$, respectively, which revealed that rapid economic growth relied on high-carbon energy consumption, which then led to more $\mathrm{CO}_{2}$ emissions. In contrast, the other two factors reducing $\mathrm{CO}_{2}$ emissions were energy intensity effect and the energy carbon structure effect. Energy intensity caused $-110.90 \mathrm{Mt} \mathrm{CO}_{2}$ emissions and energy carbon structure resulted in $-18.76 \mathrm{Mt} \mathrm{CO}_{2}$ emissions, the contribution rates of these two factors were $-43.94 \%$ and $-7.43 \%$, respectively, indicating that improving energy use efficiency and optimizing energy structure were the valid measures for reducing $\mathrm{CO}_{2}$ emissions.

The modified STIRPAT model was constructed according to ridge regression estimation, such that the elastic coefficients of the model could better reflect the response relationship between energy-related $\mathrm{CO}_{2}$ emissions and the influencing factors. With each individual factor of population size, economic activity, energy intensity and energy carbon structure increase $1 \%, \mathrm{CO}_{2}$ emissions increase, respectively, $3.13 \%, 0.41 \%, 0.30 \%$ and $0.63 \%$. We find that population expansion has the greatest potential to increase $\mathrm{CO}_{2}$ emissions, followed by economic activity effect. Due to decrease in energy intensity and energy carbon structure and both of them positively related to $\mathrm{CO}_{2}$ emissions, the two factors appear to be inhibiting features that reduce $\mathrm{CO}_{2}$ emissions, the difference is, the potential impact of energy carbon structure effect is stronger than the energy intensity one.

\subsection{Policy suggestions}

Along with rapid socio-economic development in Kazakhstan, the contradiction of excessive energy consumption and lower energy efficiency has begun to be a serious economic shackle hindering green economic development. The government of Kazakhstan has adopted a few measures aimed at mitigating energy consumption (Ardak and Yesdauletova, 2009; Ismailova, 2013), but the relationship between economic growth and $\mathrm{CO}_{2}$ emissions is still in a weak decoupling state (Xiong et al., 2015) and requires urgent optimization in the future. Based on the research, we propose some pertinent suggestions as follows:

Firstly, more clean energy or renewable energy should be exploited to optimize the energy use structure. The energy use structure of Kazakhstan still relies on traditional high-carbon energies, such as coal, oil and gas, with coal continuing to dominate overall energy consumption in Kazakhstan. In order to reduce more greenhouse gas emissions, Kazakhstan should switch to renewable resources to take the place of traditional fuels. Kazakhstan is rich in solar energy, hydropower and wind power resources, which can fully meet the domestic energy demand. However, less than $30 \%$ of water and wind resources are used to generate electricity at present (Karatayev et al., 2016). Therefore, Kazakhstan should look to develop technical assistance networks with other countries as well as vigorously develop their renewable resources.

Secondly, Kazakhstan should continue to improve the efficiency of energy utilization. As energy use efficiency mainly depends on technological progress, Kazakhstan should further its investments in advanced energy-saving technologies, and also encourage research and development in this field. At the same time, it should promote innovation in energy exploi- 
tation, transformation and utilization. Kazakhstan should as well look to exploiting its geographical advantage in the One Belt and One Road Initiative by strengthening cooperation with China around energy-related technology (Feng and Wang, 2015). Only in this way can the country improve energy efficiency and reduce energy intensity.

Thirdly, Kazakhstan should transform the concept of economic development and advocate for 'green' consumption. Additionally, the country should transform its focus from extensive growth to intensive growth, and change its economic development pattern by not only paying attention to economic quantity but also reinforcing green economy improvement. Regarding to population expansion, the country should take full advantage of media, widely advertise its green life philosophy, and advocate a low-carbon lifestyle and consumption patterns. Through these methods, Kazakhstan can both alleviate energy pressure and reduce carbon emissions.

\section{References}

Aggarwal P, Jain S, 2016. Energy demand and $\mathrm{CO}_{2}$ emissions from urban on-road transport in Delhi: Current and future projections under various policy measures. Journal of Cleaner Production, 128: 48-61.

Ang B W, 2004. Decomposition analysis for policymaking in energy: Which is the preferred method? Energy Policy, 32(9): 1131-1139.

Ang B W, 2005. The LMDI approach to decomposition analysis: A practical guide. Energy Policy, 33(7): $867-871$.

Ang B W, 2015. LMDI decomposition approach: A guide for implementation. Energy Policy, 86: $233-238$.

Ardak Yesdauletova, 2009. Kazakhstan's energy policy: Its evolution and tendencies. Journal of US-China Public Administration, 6(4): 31-39.

Arnell N W, Gosling S N, 2016. The impacts of climate change on river flood risk at the global scale. Climatic Change, 134(3): 387-401.

Azatbek T, Ramazanov A, 2016. Assessment of foreign direct investment, export and economic growth on the example of Kazakhstan. Investment Management and Financial Innovations, 13(4): 129-135.

Bahgat G, 2010. Energy partnership: China and the Gulf States. OPEC Energy Review, 29(2): 115-131.

Blank S, 1995. Energy, economics and security in Central Asia: Russia and its rivals. Central Asian Survey, 14(3): 64.

Caillaud S, Kalampalikis N, Flick U, 2012. The social representations of the Bali Climate Conference in the French and German Media. Journal of Community and Applied Social Psychology, 22(4): 363-378.

Feng Z, Wang H, 2015. The mode of economic cooperation in the "One Belt and One Road" Construction. New Paradigm for International Business, 20(2): 35-58.

Hoerl A E, Kennard R W, 1970. Ridge Regression: Application to nonorthogonal problems. Technometrics, 12(1): 69-82.

Holdren J P, Ehrlich P R, 1974. Human population and the global environment: Population growth, rising per capita material consumption, and disruptive technologies have made civilization a global ecological force. American Scientist, 62(3): 282-292.

IPCC, 2007. Summary for Policymakers. In: Climate Change 2007: The Physical Science Basis. Contribution of Working Group I to the Fourth Assessment Report of the Intergovernmental Panel on Climate Change. Cambridge, United Kingdom and New York, NY, USA: Cambridge University Press.

Ismailova D, 2013. Some trends in energy policy of Kazakhstan. European Journal of Business and Economics, 3: 9-11.

Jiang Y L, Feng L G, 2006. Transport-related resource and environmental issues in China. World Transport Policy and Practice, 12(4): 17-28. 
Kalyuzhnova Y, Patterson K, 2016. Kazakhstan: Long-term economic growth and the role of the oil sector. Comparative Economic Studies, 58(1): 93-118.

Karatayev M, Clarke M L, 2016. A review of current energy systems and green energy potential in Kazakhstan. Renewable and Sustainable Energy Reviews, 55: 491-504.

Karatayev M, Hall S, Kalyuzhnova Y et al., 2016. Renewable energy technology uptake in Kazakhstan: Policy drivers and barriers in a transitional economy. Renewable and Sustainable Energy Reviews, 66: 120-136.

Katenova M, Nurmakhanova M, 2017. Financial development and economic growth: The case of Kazakhstan. International Review of Business Research Papers, 13(1): 151-160.

Kaya Y, 1990. Impact of carbon dioxide emission control on GNP growth: Interpretation of proposed scenarios. IPCC Energy and Industry Subgroup, Response Strategies Working Group, Paris, France.

Kaya Y, Yokobori K, 1997. Environment, Energy, and Economy: Strategies for Sustainability. Tokyo, New York, Paris: United Nations University Press.

Li D Q, Wang D Y, 2016. Decomposition analysis of energy consumption for an freeway during its operation period: A case study for Guangdong, China. Energy, 97: 296-305.

Lin S, Zhao D, Marinova D, 2009. Analysis of the environmental impact of China based on STIRPAT model. Environmental Impact Assessment Review, 29(6): 341-347.

Lin S J, Beidari M, 2015. Energy consumption trends and decoupling effects between carbon dioxide and gross domestic product in South Africa. Aerosol and Air Quality Research, 15(7): 2676-2687.

Liu Y, Yang Z, Wu W, 2015. Assessing the impact of population, income and technology on energy consumption and industrial pollutant emissions in China. Applied Energy, 155: 904-917.

Lu Z, Yang Y, Wang J et al., 2014. Factor decomposition of carbon productivity in China: Based on the Laspeyres Decomposition Method. Journal of Industrial Technological Economics, 61: 1893-1896.

Macgregor J, 2017. Determining an optimal strategy for energy investment in Kazakhstan. Energy Policy, 107: $210-224$

Mao Z, 2014. Cosmopolitanism and global risk: News framing of the Asian financial crisis and the European debt crisis. International Journal of Communication, 8(1): 1029-1048.

Marquardt D W, Snee R D, 1975. Ridge regression in practice. American Statistician, 29(1): 3-20.

Mccarl B A, Adams D M, Alig R J et al., 2016. Effects of global climate change on the US forest sector: Response functions derived from a dynamic resource and market simulator. Climate Research, 15(3): 195-205.

Meyers S, Schmitt B, Chester-Jones M et al., 2016. Energy efficiency, carbon emissions, and measures towards their improvement in the food and beverage sector for six European countries. Energy, 104: 266-283.

Moutinho V, Moreira A C, Silva P M, 2015. The driving forces of change in energy-related $\mathrm{CO}_{2}$ emissions in Eastern, Western, Northern and Southern Europe: The LMDI approach to decomposition analysis. Renewable and Sustainable Energy Reviews, 50: 1485-1499.

Movkebaeva G A, 2013. Energy cooperation among Kazakhstan, Russia, and China within the Shanghai Cooperation Organization. Russian Politics and Law, 51(1): 80-87.

Nicogossian A, Stabile B, Kloiber O et al., 2017. Climate change and global health in the 21st century: Evidence and resilience. World Medical and Health Policy, 9(3): 280-282.

Ouyang X, Lin B, 2015. An analysis of the driving forces of energy-related carbon dioxide emissions in China's industrial sector. Renewable and Sustainable Energy Reviews, 45: 838-849.

Ozturk I, Acaravci A, 2010. $\mathrm{CO}_{2}$ emissions, energy consumption and economic growth in Turkey. Renewable and Sustainable Energy Reviews, 14(9): 3220-3225.

Parkhomchik L, Syrlybayeva B, 2016. Evaluation of the shale gas potential in Kazakhstan. Shale Gas: Ecology, Politics, Economy. Cham: Springer, 193-204.

Ramlall I, 2017. Internalizing $\mathrm{CO}_{2}$ emissions via central banks' financials: Evidence from the world. Renewable and Sustainable Energy Reviews, 72: 549-559.

Rowland R H, 2001. Regional population change in Kazakhstan during the 1990s and the impact of nationality population patterns: Results from the recent census of Kazakhstan. Post-Soviet Geography and Economics, 42(8): 571-614. 
Ruziev K, Majidov T, 2013. Differing effects of the global financial crisis on the Central Asian Countries: Kazakhstan, the Kyrgyz Republic and Uzbekistan. Europe-Asia Studies, 65(4): 682-716.

Sarbassov Y, Kerimray A, Tokmurzin D et al., 2013. Electricity and heating system in Kazakhstan: Exploring energy efficiency improvement paths. Energy Policy, 60(5): 431-444.

Sauer T J, Norman J M, Sivakumar M V K et al., 2017. Sustaining soil productivity in response to global climate change: Science, policy, and ethics. Vadose Zone Journal, 11(2): 531-531.

Schandl H, Hatfield-Dodds S, Wiedmann T et al., 2016. Decoupling global environmental pressure and economic growth: Scenarios for energy use, materials use and carbon emissions. Journal of Cleaner Production, 132(1): 45-56.

Shao S, Yang L, Gan C et al., 2016. Using an extended LMDI model to explore techno-economic drivers of energy-related industrial $\mathrm{CO}_{2}$ emission changes: A case study for Shanghai (China). Renewable and Sustainable Energy Reviews, 55: 516-536.

Streets D G, Jiang K, Hu X et al., 2001. Recent reductions in China's greenhouse gas emissions. Science, 294(5548): 1835-1837.

Swan L G, Ugursal V I, Ian B M, 2013. Hybrid residential end-use energy and greenhouse gas emissions model: Development and verification for Canada. Journal of Building Performance Simulation, 6(1): 1-23.

Tang J R, 2014. Analysis on the carbon emission in Henan Province and its influence factors based on VAR model. Sustainable Development, 4(3): 42-50.

Tunç G İ, Türüt-Aşık S, Akbostancı E, 2009. A decomposition analysis of $\mathrm{CO}_{2}$ emissions from energy use: Turkish case. Energy Policy, 37(11): 4689-4699.

Wang C, Wang F, Zhang X et al., 2017a. Examining the driving factors of energy related carbon emissions using the extended STIRPAT model based on IPAT identity in Xinjiang. Renewable and Sustainable Energy Reviews, 67: 51-61.

Wang D, Nie R, Shi H Y, 2011a. Scenario analysis of China's primary energy demand and $\mathrm{CO}_{2}$ emissions based on IPAT Model. Energy Procedia, 5: 365-369.

Wang Q, Jiang X T, Li R, 2017b. Comparative decoupling analysis of energy-related carbon emission from electric output of electricity sector in Shandong Province, China. Energy, 127: 78-88.

Wang Q, Li R, 2016. Drivers for energy consumption: A comparative analysis of China and India. Renewable and Sustainable Energy Reviews, 62: 954-962.

Wang W W, Zhang M, Zhou M, 2011b. Using LMDI method to analyze transport sector $\mathrm{CO}_{2}$ emissions in China. Energy, 36(10): 5909-5915.

Xiong C, Yang D, Huo J et al., 2015. The relationship between energy consumption and economic growth and the development strategy of a low-carbon economy in Kazakhstan. Journal of Arid Land, 7(5): 706-715.

$\mathrm{Xu}$ X, 2010. The oil and gas links between Central Asia and China: A geopolitical perspective. OPEC Energy Review, 23(1): 33-54.

York R, Rosa E A, Dietz T, 2003. STIRPAT, IPAT and ImPACT: Analytic tools for unpacking the driving forces of environmental impacts. Ecological Economics, 46(3): 351-365.

Zhang $\mathrm{C}$, Liu C, 2015. The impact of ICT industry on $\mathrm{CO}_{2}$ emissions: A regional analysis in China. Renewable and Sustainable Energy Reviews, 44(44): 12-19.

Zhang W, Li K, Zhou D et al., 2016. Decomposition of intensity of energy-related $\mathrm{CO}_{2}$ emission in Chinese provinces using the LMDI method. Energy Policy, 92: 369-381.

Zhao Y, Li H, Zhang Z et al., 2017. Decomposition and scenario analysis of $\mathrm{CO}_{2}$ emissions in China's power industry: Based on LMDI method. Natural Hazards, 86(2): 645-668. 